\title{
ELIMINATION OF X-RAY INDUCED ABERRANT CHROMOSOMES IN THE ROOT MERISTEMS OF TWO-ROWED BARLEY")
}

\author{
TAKAJI IKUSHIMA AND SADAO ICHIKAWA
}

Laboratory of Genetics, Faculty of Agriculture, Kyoto University, Kyoto

Received June 26, 1967

In our studies of radiation-induced somatic mutations in diploid oats heterozygous for the albino gene, $a l$, it was found that elimination of somatic mutant (albino) cells occurred during plant growth (Nishiyama et al. 1964, 1966, Ichikawa and Ikushima 1967). Also, it was concluded that the somatic mutations in this material often were induced through two-hit events, probably such as interstitial deletion of the chromosome segment carrying the normal gene (Nishiyama et al. 1964, 1966). Similar conclusions have been made by Sparrow and Cuany (1959), Sparrow et al. (1961), Matsumura et al. (1963) and others in several additional plant species. Amano and Smith (1965) confirmed that many of the X-ray induced mutations in corn were due to deletions. Based on these findings and conclusions, it is supposed that such an elimination of mutant cells in somatic tissues might be related to the occurrence of the deletion-type somatic mutations mentioned above. Loss of chromosome segments generally has been thought to be the main cause of death or loss of reproductive ability of individual cells by radiations. However, there has been little evidence presented which definitely prove that chromosomal losses play the main role in producing such radiation damage. Therefore, it is necessary to confirm whether or not the cells having chromosomal aberrations can survive through successive mitotic division cycles after irradiation, and how such chromosomal aberrations contribute to the depression of growth.

The present paper describes the mitotic behavior of cells carrying chromosomal aberrations in X-rayed barley root tips.

\section{MATERIALS AND METHODS}

Seeds of a cultivated variety, Schwanhals, of two-rowed barley (Hordeum distichum L., $2 \mathrm{n}=14$ ) were used. The seeds were soaked for $24 \mathrm{hrs}$ in the dark at $20 \pm 1{ }^{\circ} \mathrm{C}$ prior to irradiation. These seeds were then treated with a single moderate exposure, $300 \mathrm{R}$, of $\mathrm{X}$ rays delivered at an exposure rate of $354 \mathrm{R} / \mathrm{min}$. This exposure was selected to induce many chromosomal breaks without causing delayed or abnormal mitotic divisions. Our preliminary examination showed that exposures higher than $300 \mathrm{R}$ frequently induced a delay and abnormalities (predominantly stickiness of chromosomes) of mitosis in the same material. All the X-irradiations were performed in the light with a Philips' X-ray

1) Contribution from the Laboratory of Genetics, Faculty of Agriculture, Kyoto University, Kyoto, Japan, No. 330. 
machine operated at $200 \mathrm{kV}$ and $19 \mathrm{~mA}$, using $1.0 \mathrm{~mm} \mathrm{Al} \mathrm{filter.} \mathrm{During} \mathrm{irradiation} \mathrm{the}$ seed embryos were oriented upward in a single layer. The seeds were put back in the dark immediately after irradiation and permitted to continue the germination at the same temperature. Primary root tips were fixed with ethanol-glacial acetic acid $(3: 1)$ at six-hour intervals from 30 to $132 \mathrm{hrs}$ after soaking. Cytological preparations of the root tips ( $1.5 \mathrm{~mm}$ long) were made after staining with Feulgen's leuco-basic fuchsin, one root tip to a slide. Various types of chromosomal aberrations were scored at anaphase and metaphase. About 1000 to 1200 cells at anaphase were carefully observed at each fixation time, and 150 metaphase cells at every other fixation time. For the metaphase observations, root tips were treated with 0.05 per cent colchicine solution for two hours prior to fixation. The mitotic index also was determined at every fixation time from 5000 meristematic cells.

\section{RESULTS AND DISCUSSION}

Mitotic indices obtained from both irradiated (300R) and control root tips are presented in Table 1. The data show that there is no significant difference in the mitotic indices between the irradiated and non-irradiated root-tip meristems. However, the indices are somewhat lower in the irradiated than in the non-irradiated root tips at the earliest two fixation times, 30 and $36 \mathrm{hrs}$ after soaking, suggesting a slightly delayed onset of mitosis caused by the X-ray treatment. The indices obtained from the irradiated root tips are plotted against time after soaking in Fig. 1. The curve drawn in this figure suggests that the meristematic cells in the root tips pass through, on the average, three division cycles within $132 \mathrm{hrs}$ after soaking. The three peaks of the mitotic indices appear at 42, 78 and 120 to $126 \mathrm{hrs}$ after soaking, but the third peak is not clear probably because of a reduced synchronism after the second cycle of mitosis. Thus, a fair assessment of the cell cycle time is about $36 \mathrm{hrs}$ in this material (see Fig. 1).

The chromosomal aberrations observed were mostly of the chromosome type, agreeing well with our earlier observation (Ichikawa et al. 1965). The frequencies of dicentric

Table 1. Mitotic indices in $\mathrm{X}$-rayed $(300 \mathrm{R})$ and non-irradiated root-tip meristems determined 30 to $132 \mathrm{hrs}$ after soaking

\begin{tabular}{crr|rrr}
\hline \hline \multirow{2}{*}{$\begin{array}{c}\text { Time after } \\
\text { soaking (hr) }\end{array}$} & \multicolumn{2}{c|}{ Mitotic index $(\%)$} & \multicolumn{2}{c}{$\begin{array}{c}\text { Time after } \\
\text { soaking }(\mathrm{hr})\end{array}$} & \multicolumn{2}{c}{ Mitotic index $(\%)$} \\
\cline { 2 - 6 } & $300 \mathrm{R}$ & $0 \mathrm{R}$ & $300 \mathrm{R}$ & $0 \mathrm{R}$ \\
\hline 30 & 3.3 & 3.8 & 84 & 14.9 & 14.5 \\
36 & 17.5 & 19.3 & 90 & 11.0 & - \\
42 & 19.7 & 19.8 & 96 & 9.8 & 9.7 \\
48 & 15.8 & 16.0 & 102 & 10.1 & - \\
54 & 15.6 & 15.4 & 108 & 10.5 & 10.3 \\
60 & 10.6 & 10.7 & 114 & 11.0 & - \\
66 & 7.9 & 7.9 & 120 & 11.7 & 11.7 \\
72 & 11.8 & 11.8 & 126 & 12.1 & - \\
78 & 18.0 & - & 132 & 10.8 & 10.3 \\
\hline
\end{tabular}




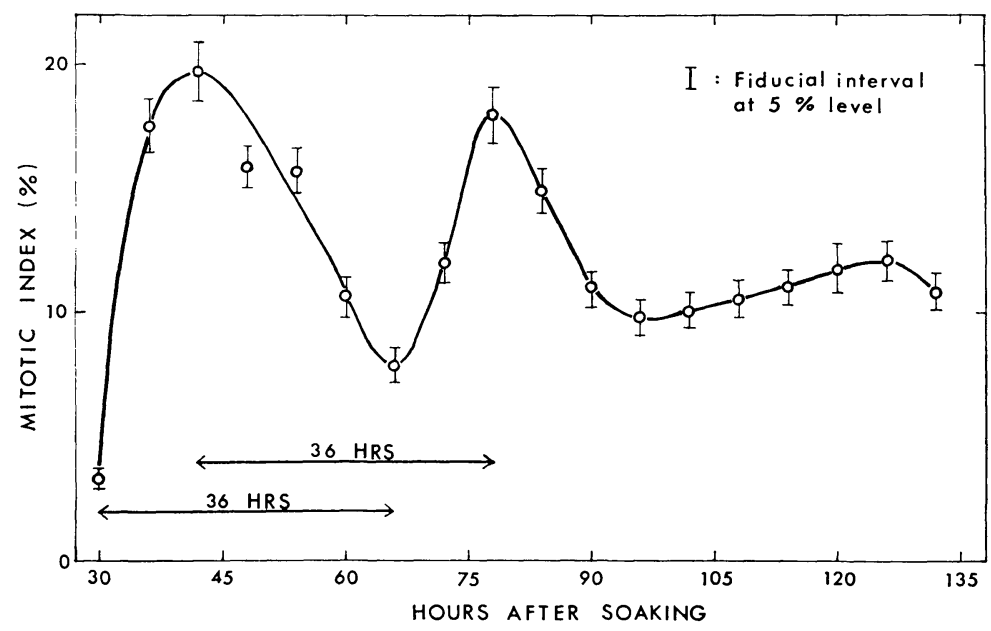

Fig. 1. Mitotic index vs. time after soaking in the barley root-tip meristems irradiated with $300 \mathrm{R}$ of $\mathrm{X}$ rays. Two horizontal arrows indicate the average cell cycle time estimated from the mitotic indices.

chromosome bridges and fragments observed at anaphase are presented in Table 2. No anaphase scoring was carried out at 30 and $36 \mathrm{hrs}$ after soaking, because anaphase figures were observed infrequently at these times. The frequencies of the dicentric bridges and fragments decrease rather rapidly as time increases. The relationship of the bridge frequency vs. time after soaking is shown in Fig. 2 . It is very clear from this figure that the number of dicentric bridges per 100 anaphase cells decreases rapidly with increasing time, i.e., with the progression of cell generation. The frequencies observed 84 and $120 \mathrm{hrs}$ after soaking are about 27 and 7 per cent of that observed at $48 \mathrm{hrs}$, respectively. These times, 48,84 and $120 \mathrm{hrs}$ after soaking, are the times when anaphase cells at the first, second and third mitotic divisions, respectively, can be observed more frequently than at any other time.

If the two centromeres of a dicentric chromosome move to the poles independently of each other, one can expect that half of the dicentric chromosomes will form bridges at anaphase. Indeed, Conger (1965) observed that 47 per cent of the dicentrics in Tradescantia microspores failed to form bridges at anaphase. The dicentrics whose two centromeres moved to the same pole thus forming no bridge will be transmitted into the next cell generation, while those which formed bridges will not be passed on as dicentrics unless they undergo a breakage-fusion-bridge cycle. McClintock (1941) reported that the breakage-fusion-bridge cycle continues through successive cell generations in corn gametophytes and endosperms but not in the embryos and sporophytes. Therefore, it seems reasonable to expect that the frequency of the anaphase dicentric bridges is halved every cell generation. That is, the frequencies of the dicentric bridges at the second and third cell divisions are expected to be a half and a quarter of that at the first division. The observed frequencies at the second and third divisions are obviously lower than the expectations (Fig. 2).

The frequencies of dicentrics and rings observed at metaphase also showed similar 
Table 2. Frequencies of chromosomal aberrations at anaphase in the barley root-tip meristems irradiated with $300 \mathrm{R}$ of $\mathrm{X}$ rays

\begin{tabular}{|c|c|c|c|c|c|}
\hline \multirow{2}{*}{$\begin{array}{l}\text { Time after } \\
\text { soaking (hr) }\end{array}$} & \multirow{2}{*}{$\begin{array}{l}\text { No. anaphase } \\
\text { cells observed }\end{array}$} & \multicolumn{2}{|c|}{ Dicentric bridges* } & \multicolumn{2}{|c|}{ Fragments } \\
\hline & & no. & $\begin{array}{l}\text { per } 100 \\
\text { cells }\end{array}$ & no. & $\begin{array}{c}\text { per } 100 \\
\text { cells }\end{array}$ \\
\hline \multicolumn{6}{|l|}{ Irradiated } \\
\hline 42 & 1218 & 167 & 13.7 & 182 & 14.9 \\
\hline 48 & 1034 & 146 & 14.1 & 162 & 15.7 \\
\hline 54 & 1056 & 109 & 10.3 & 178 & 16.9 \\
\hline 60 & 1079 & 89 & 8.2 & 110 & 10.1 \\
\hline 66 & 1196 & 71 & 5.9 & - & - \\
\hline 72 & 1138 & 71 & 6.2 & 65 & 5.7 \\
\hline 78 & 1151 & 66 & 5.7 & 59 & 5.1 \\
\hline 84 & 1070 & 42 & 3.9 & 45 & 4.2 \\
\hline 90 & 1106 & 42 & 3.8 & - & - \\
\hline 96 & 1051 & 24 & 2.3 & 30 & 2.9 \\
\hline 108 & 999 & 10 & 1.0 & - & - \\
\hline 120 & 1029 & 10 & 1.0 & 2 & 0.7 \\
\hline 132 & 1136 & 14 & 1.2 & - & - \\
\hline \multicolumn{6}{|l|}{ Control } \\
\hline 48 & 1057 & 3 & 0.3 & 0 & 0.0 \\
\hline
\end{tabular}

* Those of the chromosome type were scored as two bridges and those of the chromatid type as one. Almost all of the bridges observed were of the former type.

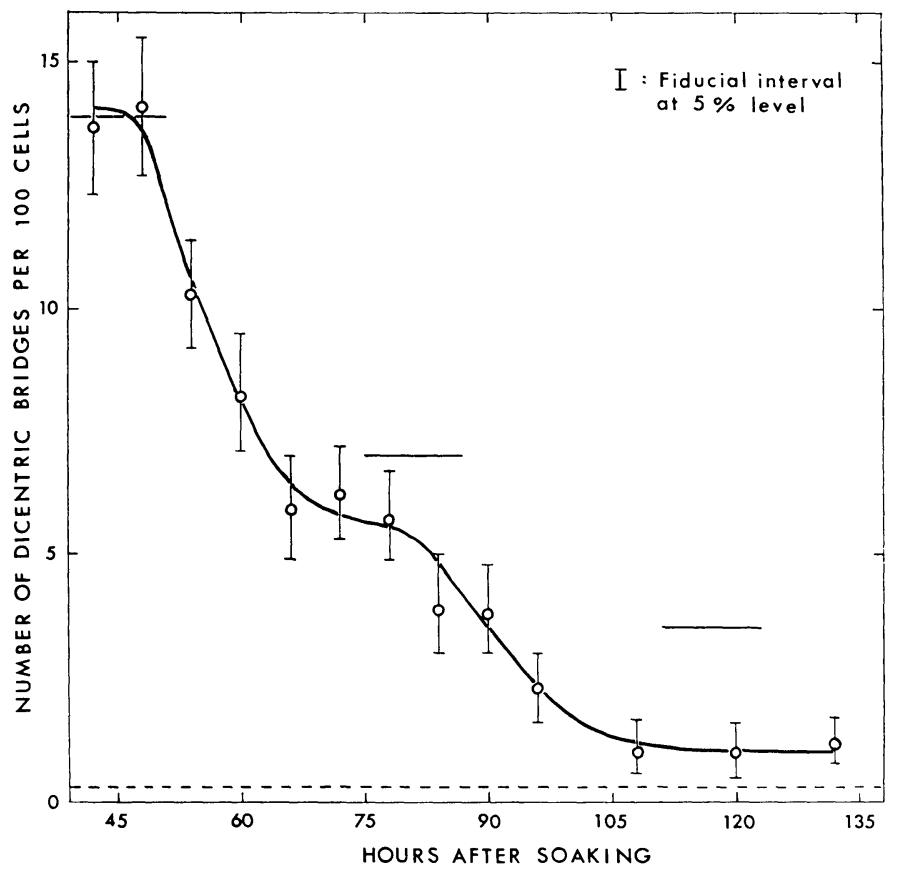

Fig. 2. Frequency of dicentric bridges at anaphase vs. time after soaking in the barley root-tip meristems irradiated with $300 \mathrm{R}$ of $\mathrm{X}$ rays. The central and right-side horizontal lines indicate the expected frequencies of dicentric bridges at the second and third mitotic divisions, $i$. $e$, a half and aquarter of the frequency at the first division (the left-side horizontal line), respectively, expectations based on an assumption that 50 per cent of dicentric chromosomes form bridges at anaphase (see text). 
Table 3. Frequencies of chromosomal aberrations at metaphase in the barley root-tip meristems irradiated with $300 \mathrm{R}$ of $\mathrm{X}$ rays

\begin{tabular}{|c|c|c|c|c|c|c|c|}
\hline \multirow{2}{*}{$\begin{array}{l}\text { Time after } \\
\text { soaking (hr) }\end{array}$} & \multirow{2}{*}{$\begin{array}{l}\text { No. metaphase } \\
\text { cells observed }\end{array}$} & \multicolumn{2}{|c|}{ Dicentrics } & \multicolumn{2}{|c|}{ Rings } & \multicolumn{2}{|c|}{ Deletions* } \\
\hline & & no. & $\begin{array}{c}\text { per } 100 \\
\text { cells }\end{array}$ & no. & $\begin{array}{c}\text { per } 100 \\
\text { cells }\end{array}$ & no. & $\begin{array}{c}\text { per } 100 \\
\text { cells }\end{array}$ \\
\hline \multicolumn{8}{|l|}{ Irradiated } \\
\hline 36 & 150 & 17 & 11.3 & 6 & 4.0 & 28 & 18.7 \\
\hline 48 & 150 & 14 & 9.3 & 4 & 2.7 & 30 & 20.0 \\
\hline 60 & 150 & 5 & 3.3 & 2 & 1.3 & 17 & 11.3 \\
\hline 72 & 150 & 5 & 3.3 & 1 & 0.7 & 11 & 7.3 \\
\hline 84 & 150 & 4 & 2.7 & 2 & 1.3 & 9 & 6.0 \\
\hline 96 & 150 & 2 & 1.3 & 1 & 0.7 & 8 & 5.3 \\
\hline 120 & 150 & 0 & 0.0 & 0 & 0.0 & 5 & 3.3 \\
\hline \multicolumn{8}{|l|}{ Control } \\
\hline 48 & 150 & 0 & 0.0 & 0 & 0.0 & 0 & 0.0 \\
\hline
\end{tabular}

* The chromosomes with detectable deletions.

rapid decreases (Table 3). The frequencies of the dicentrics presented in this table are apparently lower than those at anaphase shown in Table 2. The lower frequencies at metaphase are due mainly to our scoring method, i.e., at anaphase a "one" chromosometype bridge was scored as two (see the footnote of Table 2), while all the dicentrics detected at metaphase were of the chromosome type and were scored as one. However, the frequencies at metaphase are still lower than the expected result of twice the anaphase value (i.e., they should be nearly equal to each other by our scoring method), an assumption based on the random movement of the two centromeres of the dicentrics mentioned above (compare 11.3 per 100 metaphase cells with a half of 13.7 per 100 anaphase cells at 36 and $42 \mathrm{hrs}$ after soaking, respectively). Thus the lower frequencies may also be connected with the following: For the metaphase observations, only the cells whose chromosomes were well spread and separated from each other were scored. Therefore, it seems highly probable that the cells having dicentric chromosomes might have been excluded from the samples more frequently than those with no aberrations or those with only simple interchanges. A non-random movement of the two centromeres of the dicentric chromosomes is another possibility which cannot be ruled out. Namely, if more than 50 per cent of the dicentrics formed bridges at anaphase, a similar result could be obtained. This latter possibility seems, however, rather remote when Conger's (1965) results and the inaccuracy of the scorings at metaphase are taken into consideration. Thus the main cause of the discrepancy between the frequencies at metaphase and those at anaphase is considered to be the difficulty of accurately scoring the dicentrics at metaphase.

The frequency of acentric fragments observed at anaphase decreased from cycle to cycle of mitosis at about the same rate as dicentric bridges (Table 2), although the correlation of frequencies does not seem so high because of the very possibly excluded (from our scoring) fragments hidden in the chromosome masses near the poles. On the other hand, a similar but somewhat slower decreasing rate was found for the 
chromosomes having obvious deletions detected at metaphase (Table 3). A rapid decrease of various chromosomal aberrations during successive mitotic cycles in plant meristems has been observed by other workers (Thoday 1951, Wakonig-Vaartaja and Read 1962, Clowes 1963, Evans 1965, Grant 1965).

The present results indicate that a considerable amount, possibly more than 50 per cent, of the cells carrying dicentric chromosomes are eliminated from the meristematic cell population. This faster rate of decrease than expected for dicentric bridges (Fig. 2) seems to be attributable to an inferior reproductive ability or loss of reproductive integrity of the cells carrying induced dicentric chromosomes. The occurrence of any dicentric chromosome is inevitably accompanied with eventual loss of chromosome segments. Radiation-induced loss of reproductive integrity of cells has been generally attributed to cell death or mitotic arrest ("permanent interphase", see Van't Hof and Sparrow 1963) probably as the result of genic or chromosomal loss or unbalance caused by chromosome aberrations, or to a premature differentiation (see Dewey and Howard 1963, Evans 1965). Evans (1965) stated that chromosomal aberration might not merit the importance usually ascribed. However, the present study suggests that loss of chromosome segments must be one of the important factors leading to loss of reproductive integrity. The question that to what extent such loss of reproductive integrity contributes to the depression of growth in multi-cellular meristems is the next problem to be solved. Although many evidences recently accumulated demonstrate the direct correlation between loss of reproductive integrity and growth inhibition in a single-meristematic-cell system, Tradescantia stamen hairs (Davies 1963, Alvarez and Sparrow 1965, Nayar and Sparrow 1967, Ichikawa and Sparrow 1967a, 1967b, 1967c, Ichikawa et al.1967), little such evidence has been obtained from multi-cellular meristems.

\section{SUMMARY}

Frequencies of chromosomal aberrations were examined during three successive cell generations in the root meristem of two-rowed barley following X-ray irradiation of 24$\mathrm{hr}$ soaked seeds with a moderate exposure of $300 \mathrm{R}$. Dicentric bridges and acentric fragments observed at anaphase and dicentrics, rings and chromosomes with obvious deletions detected at metaphase were scored. Frequencies of these chromosomal aberrations decreased rapidly with the progress of cell generation. Their rapid reduction in number, especially of the dicentric bridges which decreased much more rapidly than expected, indicates that elimination of the cells carrying aberrant chromosomes occurs in the meristematic cell population. The elimination seems to be attributable to the loss of reproductive integrity of the cells carrying such aberrations, probably as a result of the loss of chromosome segments.

\section{ACKNOWLEDGEMENTS}

The authors wish to thank Prof. K. Tsunewaki for his valuable suggestions. Discussions with Mr. E. Amano of the National Institute of Genetics, Misima, were very 
helpful and are gratefully acknowledged. The authors also acknowledge the valuable help of Miss Susan S. Schwemmer of Brookhaven National Laboratory, Upton, New York, U.S.A., in the preparation of the manuscript.

\section{LITERATURE CITED}

Alvarez, M. R., and A. H. Sparrow, 1965 Comparison of reproductive integrity in the stamen hair and root meristem of Tradescantia paludosa following acute gamma irradiation. Radiation Botany 5: $423-430$.

Amano, E., and H. H. Smith, 1965 Mutations induced by ethyl methanesulfonate in maize. Mutation Res. 2: 344-351.

Clowes, F. A. L., 1963 Micronuclei in irradiated meristem. Radiation Botany 3: 223-229.

Conger, A. D., 1965 The fate of metaphase aberrations. Radiation Botany 5: 81-96.

Davies, D. R., 1963 Radiation-induced chromosome aberrations and loss of reproductive integrity in Tradescantia. Radiation Res. 20: 726-740.

Dewey, D. L., and A. Howard, 1963 Cell dynamics in the bean root tip. Radiation Botany 3: 259-263.

Evans, H. J., 1965 Effects of radiations on meristematic cells. Radiation Botany 5: 171-182.

Grant, C. J., 1965 Chromosome aberrations and the mitotic cycle in Trillium root tips after X-irradiation. Mutation Res. 2: 247-262.

Ichikawa, S., and T. Ikushima, 1967 A developmental study of diploid oats by means of radiationinduced somatic mutations. Radiation Botany 7: 205-215.

Ichikawa, S., T. Ikushima, and I. Nishiyama, 1965 Two kinds of chromosome rejoinings in X-rayed two-rowed barley. Radiation Botany 5: 513-523.

Ichikawa, S., and A. H. Sparrow, 1967a Radiation-induced loss of reproductive integrity in the stamen hairs of Tradescantia blossfeldiana Mildbr., a twelve-ploid species. Radiation Botany 7: 333-345.

Ichikawa, S., and A. H. Sparrow, 1967b Radiation-induced loss of reproductive integrity in the stamen hairs of a polyploid series of Tradescantia species. Radiation Botany 7 (in press).

Ichikawa, S., and A. H. Sparrow, 1967c Gamma-ray induced somatic mutations in the stamen hairs of Tradescantia virginiana L., a tetraploid species (in preparation).

Ichikawa, S., A. H. Sparrow, and C.S. Takahashi, 1967 Effects of dose rate on somatic mutation rate and loss of reproductive integrity in Tradescantia stamen hairs (in preparation).

Matsumura, S., S. Kondo, and T. Mabuchi, 1963 Radiation genetics in wheat, VIII. The RBE of heavy particles from $\mathrm{B}^{10}(\mathrm{~N}, \alpha) \mathrm{Li}^{7}$ reaction for cytogenetic effects in Einkorn wheat. Radiation Botany 3: 29-40.

McClintock, B., 1941 The stability of broken ends of chromosomes in Zea mays. Genetics 26: 234282.

Nayar, G. G., and A.H. Sparrow, 1967 Radiation-induced somatic mutations and loss of reproductive integrity in Tradescantia stamen hairs. Radiation Botany 7: 257-267.

Nishiyama, I., S. Ichikawa, and E. Amano, 1964 Radiobiological studies in plants, X. Mutation rate induced by ionizing radiations at the al locus of sand oats. Radiation Botany 4: 503-516.

Nishiyama, I., T. Ikushima, and S. Ichikawa, 1966 Radiobiological studies in plants, XI. Further studies on somatic mutations induced by X-rays at the al locus of diploid oats. Radiation Botany 6: 211-218.

Sparrow, A.H., and R. L. Cuany, 1959 Radiation-induced somatic mutations in plants. In "Proc. Conf. on Radioactive Isotopes in Agriculture", pp. 153-156. U. S. A. E. C., Washington, D. C.

Sparrow, A. H., R. L. Cuany, J. P. Miksche, and L. A. Schairer, 1961 Some factors affecting the response of plants to acute and chronic radiation exposures. Radiation Botany 1: 10-34.

Thoday, J. M., 1951 The effect of ionizing radiations on the broad bean root. IX. Chromosome breakage and the lethality of ionizing radiations to the root meristem. Brit. J. Radiol. 24: 622-628.

Van't Hof, J., and A. H. Sparrow, 1963 Growth inhibition, mitotic cycle time and cell number in chronically irradiated root meristems of Pisum. Radiation Botany 3: 239-247. 
Wakonig-Vaartaja, R., and J. Read, 1962 Growth reduction, chromosome damage and mitotic inhibition produced in roots of Vicia faba by X-rays and by triethylene melamine. Radiation Botany 2: 53-63. 